\title{
TRABALHO, PERFIL DOCENTE E CURRÍCULO: A Formação Profissional Inconclusa no Ensino Médio Integrado do IFPR
}

\author{
Cássia Maria França de Sousa Fernandes ${ }^{1}$ \\ Renan Bandeirante de Araújo \\ Igor Mateus Batista ${ }^{3}$
}

\begin{abstract}
RESUMO
Este artigo fundamentou-se nas análises desenvolvidas pelo Grupo de Pesquisa do CNPq “Economia do Trabalho, Educação e Desenvolvimento Regional", bem como dos resultados parciais de pesquisas realizadas junto ao Programa de Pós-Graduação em Ensino: Formação Docente Interdisciplinar, da Universidade Estadual do Paraná. Realizou-se um recorte em que foram analisadas as incongruências formativas no Ensino Médio Integrado oferecido pelo Instituto Federal do Paraná (IFPR). Por meio de uma pesquisa qualitativa ancorada em análises bibliográficas e em fontes documentais, identificaram-se o perfil profissional docente do professor atuante no IFPR bem como a concepção de Ensino Profissional proposta nos Projetos Pedagógicos dos cursos das modalidades analisadas, cursos ofertados na mesorregião metropolitana de Curitiba, mais precisamente nos campi de Campo Largo, Curitiba e Pinhais. Os resultados alcançados revelaram que os cursos pesquisados têm sua ênfase centrada na formação para o mercado de trabalho, ainda que o Ensino Médio Integrado seja a última etapa da Educação Básica, portanto de caráter formativo. A prevalência da concepção formativa técnica unilateral implica que as aulas são ministradas, exceção à regra, por professores bacharéis, com reduzida carga horária das disciplinas de Ciências Humanas e Sociais no eixo Formação Técnica e Profissional.
\end{abstract}

Palavras-chave: Formação docente. Ensino Médio Integrado. Currículo Técnico/Profissional. Omnilateralidade.

\section{WORK, TEACHER PROFILE AND CURRICULUM: INCONCLUSIVE VOCATIONAL TRAINING IN THE IFPR'S INTEGRATED HIGH SCHOOL}

\section{ABSTRACT}

This paper was based on the analyzes developed by the CNPq Research Group "Labor Economics, Education and Regional Development", as well as the partial results of research carried out within the Graduate Program in Education: Interdisciplinary Teacher Training at the State University of Paraná, Brazil. A cutoff of the research was made in which the formative inconsistencies in the Integrated High School offered by the Federal Institute of Paraná (IFPR) were analyzed. Through a qualitative research anchored in bibliographic analyzes and in documentary sources, the professional profile of the teacher working at the IFPR was identified, as well as the concept of Professional Education proposed in the Pedagogical Projects of the courses of the modalities analyzed, courses offered in the metropolitan mesoregion from Curitiba, more precisely at the campuses of Campo Largo, Curitiba and Pinhais The results achieved revealed that the courses researched have their emphasis centered on training for the job market, even though Integrated High School is the last stage of Basic Education, therefore, of a formative character. The prevalence of the unilateral technical formative conception implies that the classes are mostly taught by bachelor teachers, with reduced workload of the disciplines of Human and Social Sciences in the Technical and Vocational Training axis.

Keywords: Teacher training. Integrated High School. Technical/Vocational Curriculum. Omnilaterality.

\author{
RECEBIDO EM: 2/3/2020
}

ACEITO EM: 21/6/2020

\footnotetext{
1 Universidade Estadual do Paraná - Campus Paranavaí. Paranavaí/PR, Brasil. http://lattes.cnpq.br/1361071123357918. https://orcid.org/00000003-2528-2801. cassiafranca8@gmail.com

2 Universidade Estadual do Paraná - Campus Paranavaí. Paranavaí/PR, Brasil. http://lattes.cnpq.br/9293271922485263. https://orcid.org/00000001-6199-1061. renanbandeirante@gmail.com

3 Autor correspondente. Universidade Estadual do Paraná - Campus Paranavaí. Av. Gabriel Esperidião, s/n - Jd. Morumbi. CEP 87703-000. Paranavaí/PR, Brasil. http://lattes.cnpq.br/9027573647661731. https://orcid.org/0000-0002-4010-300X. igormateusbatista@gmail.com
} 
Este artigo analisa a formação dos professores que atuam na Educação Profissional e Tecnológica (EPT) no âmbito do Instituto Federal do Paraná (IFPR), o currículo e a formação profissional unilateral ofertada por meio do Ensino Médio Integrado. Trata-se de uma instituição de ensino cuja relevância pode ser percebida ao considerar-se sua presença em todas as mesorregiões, mais precisamente em 25 municípios do Estado do Paraná. Buscamos relacionar a formação inicial dos docentes com a matriz curricular, os objetivos propostos e o perfil profissional pretendido nos Projetos Pedagógicos de três cursos de Ensino Médio Integrado à Educação Profissional de campi pertencentes à mesorregião metropolitana de Curitiba, definidos como amostra de nosso estudo.

Verificamos que essa temática é relevante no cenário educacional brasileiro, uma vez que, de acordo com o Ministério da Educação e Cultura (MEC), no Brasil existem 38 Institutos Federais, totalizando 644 campi presentes em todas as regiões, onde, possivelmente, situações semelhantes acontecem, posto que o marco regulatório são os mesmos para a educação profissional do sistema Instituto Federal de Educação Ciência e Tecnologia (Ifet).

A análise sobre currículo, ensino técnico e formação de professores, particularmente da educação técnica profissional, tais quais os cursos ofertados pelos Institutos Federais Tecnológicos, indelevelmente remete-nos às discussões relativas à formação na perspectiva omnilateral por meio da politecnia. Tratou-se de uma proposição escudada nas reflexões críticas de Marx acerca da educação subordinada ao processo de divisão do trabalho na grande indústria, do seu caráter alienado e a correlata obliteração do indivíduo humano genérico, pois o processo de trabalho "[...] mutila o trabalhador, fazendo dele um trabalhador parcial [...] separa do trabalho a ciência como potência autônoma de produção e a obriga a servir ao capital" (MARX, 1996, p. 541).

Para Della Fonte (2014, p. 387), a "síntese da proposta marxiana de educação se expressa no vínculo entre educação e trabalho; mais precisamente, o trabalho transforma-se em princípio educativo". A denominação dessa proposta educativa ficou conhecida como educação politécnica, uma modalidade de ensino que vincula formação intelectual e técnica/prática ao desenvolvimento psicofísico do indivíduo. A educação, baseada na politecnia e na formação omnilateral, foi apresentada por Karl Marx no I Congresso Internacional dos Trabalhadores no ano de 1866 (DELLA FONTE, 2014). Vale salientar, contudo, que na obra Manuscritos Econômicos Filosóficos (1844) Marx já havia afirmado que "o homem se apropria da sua essência omnilateral de uma maneira omnilateral, portanto, como um homem total" (MARX, 2004, p. 108).

Percebe-se que há um vínculo indissociável entre a concepção de formação politécnica e a sociedade produtora de mercadoria. Isso porque a educação, com base na politecnia proposta por Marx, implica confrontar as contradições econômicas e sociais que fundavam a sociedade assentada na grande indústria e os correlatos processos de obliteração do indivíduo.

A escola unitária, proposta por Antonio Gramsci, encontrou seus fundamentos nos enunciados sobre formação politécnica e omnilateral anteriormente esboçados por Karl Marx. O intelectual sardo, por meio da educação integral, visava a justamente alcançar uma formação totalizante do indivíduo na perspectiva da sua emancipação e da construção do sujeito crítico/ativo. Gramsci, de acordo com Schlesener (2002, p. 68), 
objetivava a constituição de "uma escola que formasse a nova geração de produtores, isto é, uma escola que preparasse técnicos que não fossem apenas executores mecânicos, mas que dominassem a sua arte ao adquirir o saber sobre a técnica, seus limites e possibilidades".

De modo a explicitar o sentido das reflexões desenvolvidas inicialmente por Marx e, posteriormente, por Gramsci, Manacorda (2007) enfatiza que o princípio da educação profissional, na perspectiva do politecnicismo e da omnilateralidade, implica que

O primeiro termo, ao propor uma preparação pluriprofissional, contrapõe-se à divisão do trabalho específica da fábrica moderna; o segundo, ao prever uma formação unificadamente teórica, opõe-se à divisão originária entre o trabalho intelectual e trabalho manual, que a fábrica moderna exacerba (p. 48).

Temos que, ao reinterpretar Marx e Gramsci, particularmente rever o papel social da educação, numa perspectiva de superação dos dilemas inerentes à sociedade, calcada na divisão do trabalho e elaboração de um processo de ensino com vistas ao desenvolvimento pleno do gênero humano. $\mathrm{O}$ autor quer, justamente, enfatizar que a "[...] divisão cria unilateralidade e, sob o signo da unilateralidade, justamente, se reúnem todas as determinações negativas, assim como sob o signo oposto, o da omnilateralidade [...], reúnem-se todas as perspectivas positivas da pessoa" (MANACORDA, 2007, p. 78).

$\mathrm{Na}$ contemporaneidade, referenciados na tese da formação integral preconizada pela escola unitária, diversos educadores(as) têm procurado articular suas análises em torno do eixo trabalho e educação, a saber; Gaudêncio Frigotto (2007), Maria Ciavatta (2018), Marise Ramos (2014), Acácia Kuenzer (2016, 2017) e Demerval Saviani (2013). Ainda que com nuances, esses estudiosos(as), em síntese sumária, filiam-se às interpretações de Marx e Gramsci trazidas por Manacorda (2007).

Essa aproximação interpretativa fica patenteada, por exemplo, na análise desenvolvida por um autor expoente da corrente pedagógica nominada de Histórico-Crítica, particularmente quando da análise de que uma proposta de ensino profissional que visa a integrar ciência, tecnologia, trabalho e cultura, na perspectiva politécnica, implica a busca pela formação omnilateral do homem; "[...] um desenvolvimento multilateral [...] que abarca todos os ângulos da prática produtiva moderna na medida em que ele domina aqueles princípios, aqueles fundamentos, que estão na base da organização da produção moderna" (SAVIANI, 1989, p. 17).

À guisa de análise, faz-se necessário reconhecer a existência das múltiplas variações do trabalho, situando a tecnologia como o centro da integração entre teoria e prática, valendo-se, porém, do aspecto omnilateral da formação como uma possibilidade de levar o homem a tornar-se detentor de conhecimentos tanto intelectuais quanto práticos. Em outros termos, podemos afirmar que a concepção de formação integra$\mathrm{da}$, que remete às postulações de politecnia, representa um caminho para conceber a educação geral articulada à formação profissional como meio para a emancipação do homem.

Na contemporaneidade, a educação profissional, aplicada na rede Ifet, visa a formar força de trabalho para suprir o mercado de emprego situado dentro de uma conjuntura política e econômica de valorização da "formação" para o mercado de emprego. 
Logo, a definição das políticas públicas da educação profissional dá-se em consonância com os princípios e as determinações do regime de acumulação flexível atual. Os Institutos Federais e, consequentemente, o IFPR, resultam desse processo a partir da política de expansão e da reforma da educação profissional dos governos do ex-presidente Luiz Inácio Lula da Silva (2003-2010) e Dilma Rousseff (2011-2016).

O IFPR figura como uma escola federal especializada na oferta da Educação Profissional Tecnológica - IPT - integrada ao Ensino Médio, entre outros níveis e modalidades. Com base na análise de documentos institucionais de domínio público, verificamos um discurso que conduz ao entendimento de que o IFPR atua em uma perspectiva politécnica de ensino, apontando como o cerne de sua proposta pedagógica a articulação entre ciência, tecnologia, trabalho e cultura.

Dada, contudo, a ambiguidade da materialização de um projeto de educação que contemple verdadeiramente a preparação para o mundo do trabalho e para o prosseguimento dos estudos, diante de uma proposta que, de fato, articule um ensino de ciência, tecnologia, trabalho e cultura, buscamos, neste artigo, analisar, sem esgotar as possibilidades de estudos posteriores, a forma pela qual regulamenta-se, estrutura-se e se institui o Ensino Médio integrado à EPT no IFPR. Para tanto, valemo-nos de uma metodologia que busca suporte em uma bibliografia capaz de conferir escopo teórico para a exposição crítica desenvolvida e para a interpretação dos documentos confrontados, mais especificamente do Projeto Pedagógico dos três cursos mais requisitados em três diferentes campi que compõem a mesorregião metropolitana de Curitiba.

Dos Projetos Político-Pedagógicos analisados, destacamos a proposição afirmativa de que "[...] o ensino a ser desenvolvido pelo Instituto Federal do Paraná representa uma significativa oportunidade de formação para o trabalho, organicamente articulada à elevação dos níveis de escolaridade" (IFPR, 2017, p. 7). Neste estudo, todavia, não verificamos a adoção de políticas necessárias para a superação do ensino fragmentado de característica tecnicista que, subordinado à lógica do mercado de emprego, constitui-se como forma predominante da educação profissional ofertada pelo IFPR.

\section{PROCEDIMENTOS METODOLÓGICOS}

Tomando por base a proposição de Netto (1998), verificamos que o método diz respeito ao problema central e polêmico em uma pesquisa. De acordo com o autor, "[...] o interesse epistemológico está sempre subordinado à direção ontológica da sua reflexão. [...] ele discute o método sempre conectando a discussão do método a um objeto preciso" (p. 79). Ou, ainda, pelo ponto de vista do método informado por Netto (1998, p. 79), é preciso "[...] a máxima fidelidade do sujeito que pesquisa ao objeto pesquisado. [...] a crítica demanda um sujeito ativo, rico em determinações. Só um sujeito criativo pode trazer à consciência um objeto concreto, que é síntese de múltiplas determinações". Com base nessas premissas, a análise desenvolvida no presente artigo articula reflexões emanadas de uma pesquisa bibliográfica teórica e da fonte documental relativa ao objeto pesquisado.

Em acordo com o método analítico supraenunciado, a pesquisa seguiu as etapas metodológicas indicadas por Gil (2002) de coleta e análise dos dados. Com o intuito de evitar a linearidade, porém, sugerida pelo autor, optou-se pela dialética, que caracteriza 
o movimento, em espiral, da intrínseca relação entre as particularidades e a universidade do objeto estudado. Assim, os diferentes momentos da pesquisa podem ser sintetizados na adoção dos seguintes movimentos: busca das fontes enquanto procedimento de coleta de dados; leitura do material e feitura dos respectivos fichamentos; organização lógica do assunto para posterior tratamento dos dados; e, por fim, redação do texto e finalização do processo de análise propriamente dito.

A considerar as contradições relativas à modalidade de Educação Profissional e Técnica ofertada pelo IFPR, questionamo-nos sobre como efetiva-se sua construção, a considerar suas múltiplas determinações, o que nos levou à coleta de dados em documentos institucionais para análise e compreensão da dinâmica adotada pelo IFPR na introdução da formação técnica profissional de nível médio na etapa final da Educação Básica: o Ensino Médio.

Como referência e contraponto da formação ofertada pelo IFPR, conforme análise nas seções que se seguem, tem-se a experiência do curso de Licenciatura em Computação do Instituto Federal de Educação, Ciência e Tecnologia do Rio Grande do Sul (Iffar), campus Santo Augusto, cuja proposta de currículo, intitulado Componente Curricular Articulador, apresenta resultados favoráveis no que se refere à formação continuada de professores e na formação profissional e humana de estudantes, que alie teoria e prática na resolução de problemas na execução da profissão (CAMBRAIA; PEDROSO, 2017).

Por meio do Componente Curricular Articulador, intitulado Prática do Ensino da Computação (PEC) e do Desenvolvimento Profissional Docente na Licenciatura em Computação (DPDLiC), a experiência na aplicação do currículo integrador patenteia, de acordo com Cambraia e Pedroso (2017, p. 24), que se "potencializa uma relação dialética entre teoria e prática, que se dissemina no curso pelo diálogo estabelecido entre professores/formadores" e estudantes, de modo a superar a dicotomia estabelecida pelos cursos de currículo integrado em que predominam as disciplinas técnicas e a carência de formação pedagógica aos bacharéis, acarretando na predominância de uma racionalidade técnica para atender mercados de trabalho em detrimento de formação para o exercício da cidadania.

Os documentos institucionais foram coletados em consulta realizada no site do IFPR. Selecionamos aqueles pertinentes à pesquisa que nos auxiliaram na busca pela compreensão da perspectiva adotada pela instituição para a estruturação do Ensino Médio técnico Integrado à EPT, em atendimento à proposta de formação que se materializa por intermédio das diretrizes que orientam essa modalidade de ensino e suas especificidades.

Desse modo, o cerne privilegiado deste trabalho esteve no estudo do Projeto Pedagógico de Curso (PPC) de três ${ }^{4}$ cursos ofertados pelos campi do IFPR da mesorregião de Curitiba, sendo eles: Curso Técnico em Automação Industrial, situado na cidade de Campo Largo; Curso Técnico em Contabilidade, localizado em Curitiba; e Curso Técnico em Administração, na cidade de Pinhais, nessa respectiva ordem.

\footnotetext{
Neste artigo elencamos somente três relevantes Projetos Pedagógicos de curso do Ifet-PR. Para acesso do resultado completo da pesquisa ver: FERNANDES, Cássia Maria França de Sousa. Formação docente e educação: os limites do Ensino Tecnicista do Instituto Federal do Paraná. 2019. Dissertação (Mestrado) - Universidade Estadual do Paraná, Paranavaí, 2019.
} 
Nos PPCs focamos nossas análises na matriz curricular, bem como nos objetivos e no perfil profissional do egresso de cada curso. Realizamos, também, uma investigação da formação inicial dos docentes que atuam nessas unidades do IFPR, tendo em vista o papel fundamental desse profissional na formação da classe trabalhadora.

Escolhemos o Campus de Curitiba por ser a maior unidade administrativa na mesorregião analisada, com um quantitativo maior de docentes, conforme mostra a Tabela 1, e também de discentes, apresentada na Tabela 2, permitindo maior alcance nos dados de nossa pesquisa.

Tabela 1 - Quantitativo docente lotado na mesorregião pesquisada

\begin{tabular}{l|c|c|c|c}
\multicolumn{1}{c|}{ Campi } & $\begin{array}{c}\text { Cursos de } \\
\text { Ensino Médio } \\
\text { Integrado }\end{array}$ & $\begin{array}{c}\text { Cursos } \\
\text { Analisados }\end{array}$ & $\begin{array}{c}\text { Total de } \\
\text { docentes da unidade }\end{array}$ & $\begin{array}{c}\text { Docentes } \\
\text { bacharéis }\end{array}$ \\
\hline Campo Largo & 2 & 1 & 53 & 30 \\
\hline Curitiba & 8 & 1 & 210 & 141 \\
\hline Pinhais & 2 & 1 & $\mathbf{2 9 1}$ & 134 \\
\hline Total & $\mathbf{1 2}$ & $\mathbf{3}$ & \\
\hline
\end{tabular}

Fonte: Elaborada pelos autores com base em informações retiradas de Info - IFPR 5 .

Tabela 2 - Total de alunos atendidos em cada unidade da mesorregião geográfica metropolitana e Curitiba

\begin{tabular}{l|c|c|c}
\hline \multicolumn{1}{c|}{ Campi } & Alunos presenciais & Alunos EaD & $\begin{array}{c}\text { Alunos do Ensino } \\
\text { Médio Integrado }\end{array}$ \\
\hline Campo Largo & 815 & 0 & 282 \\
\hline Curitiba & 3.951 & 1.286 & 1.407 \\
\hline Pinhais & 331 & 6.235 & 312 \\
\hline Total por modalidade & $\mathbf{5 . 0 9 7}$ & $\mathbf{7 . 5 2 1}$ & $\mathbf{2 . 0 0 1}$ \\
\hline Total Geral & \multicolumn{3}{|c}{$\mathbf{1 8 . 6 9 5}$} \\
\hline
\end{tabular}

Fonte: Elaborada pelos autores com base em informações retiradas de Info - IFPR.

É importante destacarmos que, de acordo com a Pró-Reitoria de Gestão de Pessoas (Progepe), o IFPR possui 1.193 docentes efetivos. Na mesorregião metropolitana, considerando as cidades de Campo Largo, Pinhais e Curitiba, encontram-se lotados um total de 291 docentes, dos quais 184 são professores com formação inicial em bacharelado (dados atualizados em agosto de 2018 no site de informações do IFPR). 


\section{EDUCAÇÃO PROFISSIONAL E TÉCNICA INTEGRADA AO ENSINO MÉDIO: O CASO DO IFPR}

De acordo com o Projeto Político Pedagógico (PPP) do Campus Curitiba, o IFPR é uma instituição parte da Rede Federal de Ensino que tem por objetivo fomentar o desenvolvimento socioeconômico e regional a partir dos arranjos produtivos locais, por meio da criação de novas tecnologias com vistas à formação de profissionais aptos a analisar, intervir e transformar os processos produtivos e distributivos de geração de renda da comunidade local e regional na qual se inserem.

Partindo dessa premissa, destacamos que o IFPR, conforme prevê o artigo 7o, inciso I, e o artigo 8ㅇ da Lei no 11.892/2008 (BRASIL, 2008a), dispõe de poder e hegemonia para definir os rumos da formação que irá desenvolver, ressaltando que seu maior número de vagas, $50 \%$ do total ofertado, destina-se à EPT, prioritariamente na modalidade integrada ao Ensino Médio.

Para cumprir a responsabilidade social que lhe é atribuída e, ainda, para atuar com oferta de uma Educação Básica (técnica e superior) de qualidade, o ingresso nos cursos regulares da Educação Profissional Técnica na modalidade integrada ao Ensino Médio do IFPR ocorrem por meio de processo seletivo público, executado mediante edital específico pautado

[...] numa política de valorização das ações afirmativas, com $40 \%$ das vagas dos cursos destinadas aos estudantes provenientes de escolas públicas, $20 \%$ destinadas aos estudantes de cor preta, 5\% destinadas aos estudantes com deficiência e 5\% destinadas aos descendentes de índios (IFPR, 2017, p. 37).

Consequentemente, nos campi, de acordo com a Resolução no 54/2011, o número de cursos e de vagas a ser ofertado é definido pelo Colégio Dirigente da unidade, em consonância com o estabelecido no Projeto Pedagógico de cada curso, observando a capacidade de trabalho do quadro docente e a disponibilidade de salas de aula e de laboratórios. A mesma Resolução define, em seu artigo $24, \S 1$ 으 que se entenda "[...] como capacidade de trabalho do quadro docente as atividades de ensino, pesquisa, extensão e outras de caráter administrativo-pedagógicas desenvolvidas semanalmente pelo professor [...]" (IFPR, 2011b, p. 11).

A educação, no entanto, deve ser percebida no contexto das contradições sociais, e esse poder e hegemonia para gerir o processo educativo podem ou não priorizar uma formação com foco na integração, ou tão somente optar por outra de caráter fragmentário e pragmático, utilizando-se de um discurso que conduza ao entendimento de que vigora uma proposta de ensino verdadeiramente integrado (FERRETTI, 2016). Nesse sentido, para o sucesso dessa modalidade de ensino faz-se necessária uma integração curricular entre o ensino propedêutico e o ensino técnico, porém, em nossa análise, verificamos que essa integração é subjetiva à interpretação que o IFPR faz das diretrizes e dos marcos legais que orientam o Ensino Médio Integrado, mesmo em relação às normativas institucionais, posto que sua efetivação depende, principalmente, do agente mais importante nesse processo: o professor. 
Ciavatta (2005, p. 84) esclarece que, na modalidade de formação profissional integrada ao Ensino Médio, a expectativa é de que a educação geral ocorra de modo inseparável da "[...] educação profissional em todos os campos onde se dá a preparação para o trabalho: seja nos processos produtivos, seja nos processos educativos como a formação inicial, como o ensino técnico, tecnológico ou superior". Para tanto, é preciso haver um ensino sensível a essas questões, que, neste caso, encontra materialização na figura docente, tanto na atividade letiva quanto na atividade pedagógica, e na elaboração de documentos institucionais indispensáveis à atividade escolar, como o planejamento didático, a concepção do PPP do campus ou de um Projeto Pedagógico de Curso (PPC).

Ocorre, porém, que muitos dos professores dessa instituição possuem Graduação em bacharelado e ingressam no IFPR apenas com esse título, ou, ainda, são mestres e doutores com título obtido em programas profissionais de Pós-Graduação stricto sensu com pesquisas específicas de tecnologia, de engenharia, de informática, etc., e não possuem formação pedagógica para a docência, gerando dificuldades quanto às questões didático-pedagógicas, como a elaboração de um planejamento coerente com os critérios que a instituição previu no PPP do campus de Curitiba.

Seguindo uma premissa semelhante a esse pensamento, Damascena, Nascimento e Moura (2017) esclarecem que, especificamente no caso de professores da educação profissional, é fundamental assimilarmos que, pelas especificidades da modalidade, faz-se necessária uma formação que observe os pormenores característicos da docência, assim como inclua os saberes específicos da área de conhecimento tecnológico em questão.

Desse modo, considerando a relação trabalho docente e o currículo do Ensino Profissional Técnico ofertado pelo IFPR, apresentamos, em seguida, a análise de três PPCs de diferentes cursos Técnicos Integrado ao Ensino Médio dos campi localizados na região da Grande Curitiba, a saber: Campus de Campo largo, Campus de Curitiba e Campus de Pinhais.

\section{Curso Técnico em Automação Industrial - campus Campo Largo}

Ao analisarmos o PPC do Curso Técnico em Automação Industrial Integrado ao Ensino Médio, verificamos que sua oferta pelo campus de Campo Largo parte da ideia de ofertar Educação Profissional proporcionando aos "[...] sujeitos sociais, por meio de um currículo integrado ao mundo do trabalho" (IFPR, 2015, p. 7), uma formação que dialogue com os saberes de diversas áreas de conhecimento, pois

O compromisso social do IFPR é contribuir para o desenvolvimento local e regional com ações que contemplem na concepção de educação tecnológica e profissional, e não apenas de operacionalização ou instrumentalização de pessoas para o trabaIho, determinado por um mercado de trabalho (IFPR, 2015, p. 7).

É destacada desse excerto a tese de que o IFPR visa a contribuir para o desenvolvimento regional com base em uma educação que permita formação tecnológica e profissional para além de uma formação instrumentalizada e centrada tão somente nas funções operacionais, a considerar os objetivos propostos no artigo, ou seja, analisar 
criticamente a formação oferecida pelo IFPR por meio do Curso Técnico Integrado ao Ensino Médio. O Quadro 1 mostra alguns aspectos importantes do PPC do curso Técnico em Automação Industrial.

Quadro 1 - Curso Técnico em Automação Industrial - Campus Campo Largo

\begin{tabular}{|c|l|}
\hline Nome do curso & Técnico em Automação Industrial \\
\hline Eixo tecnológico & Controle e Processos Industriais \\
\hline Duração & 4 anos \\
\hline Carga horária & 4.880 horas-relógio \\
\hline Objetivo & $\begin{array}{l}\text { Propiciar aos discentes conhecimentos gerais, apoiados em bases } \\
\text { científicas e tecnológicas, da autonomia intelectual, do pensamento } \\
\text { crítico, da capacidade para interpretação e elaboração de projetos na } \\
\text { área de atuação; [...] Promover a socialização e a democratização do } \\
\text { conhecimento promovendo a relação dialógica entre ensino, pesquisa, } \\
\text { extensão e empreendedorismo inovador, formando profissionais } \\
\text { cidadãos que contribuam para o desenvolvimento do mundo do } \\
\text { trabalho. }\end{array}$ \\
\hline Perfil do egresso \\
$\begin{array}{l}\text { O técnico em Automação Industrial está apto para atuar no projeto, } \\
\text { execução, instrumentação e instalação de sistemas de controle e } \\
\text { automação utilizados nos processos industriais; na manutenção, } \\
\text { mediçães e testes em equipamentos utilizados em automação de } \\
\text { processos industriais; Compreender os fundamentos científico- } \\
\text { tecnológicos, por meio de atividades teóricas e práticas; Programar, } \\
\text { operar e manter sistemas automatizados, respeitando as normas } \\
\text { técnicas e de segurança com possibilidade de atuação em diversos } \\
\text { processos de fabricação industrial. }\end{array}$ \\
\hline
\end{tabular}

Fonte: Adaptado pelos autores a partir do Projeto Pedagógico do curso Técnico em Automação Industrial - Campus Campo Largo (IFPR, 2015).

Observa-se que o PPC do curso em análise coloca em relevo a importância e o compromisso em atender a necessidade local, pois a função social do IFPR articula-se às ações voltadas a impulsionar o desenvolvimento local e regional. Relacionado às políticas de desenvolvimento, o mesmo PPC salienta que o curso em Automação Industrial tem como um dos seus objetivos promover a relação dialógica entre ensino, pesquisa, extensão e empreendedorismo inovador. Com isso, acentua-se uma formação consoante às necessidades do mercado de emprego contemporâneo, pois a tese subsumida no conceito do "empreendedorismo inovador", como tendência, esvazia o caráter formador da Educação Tecnológica Profissional ofertada. De acordo com Acácia Kuenzer (2016),

[...] o trabalhador, cada vez mais precisará ter um amplo domínio sobre a ciência, sobre o trabalho e sobre a cultura, agora mediados por novas e diferentes formas de linguagem que se integram segundo os interesses da acumulação capitalista; esse domínio é necessário para que o trabalhador possa exercer a diferenciação crítica sobre seus usos e finalidades não explicitadas, assim como autonomia para trabalhar intelectual e eticamente [...] (p. 50).

Nessa perspectiva, a adequação da EPT às novas tendências do mundo do trabaIho reestruturado é patenteada nos objetivos do PPC do curso em questão. Da análise, evidenciamos o compromisso do IFPR em oferecer uma formação matizada pelos in- 
teresses do mercado de emprego em detrimento da ação formativa que é exigida no Ensino Médio. Quanto ao perfil do egresso, prima-se pelo profissional polivalente, capaz de atuar em diversas etapas do processo produtivo, com disponibilidade e maximização das suas capacidades físicas e psíquicas. Na EPT encontramos os estudos das habilidades e das competências que corroboram a construção da "emulação consentida" preconizada pelos princípios Toyotistas. Caso o mercado do emprego não utilize a totalidade da força de trabalho disponível, faz-se necessário saber "empreender", daí os conteúdos voltados ao ensino do "empreendedorismo inovador", objetivo do curso em Automação Industrial.

Da análise da matriz curricular do curso Técnico Integrado ao Ensino Médio em Automação Industrial, conforme o Quadro 1, debruça-se sobre a carga horária dedicada à formação humana das disciplinas do eixo tecnológico Ciências Humanas e suas tecnologias, História, Geografia, Filosofia e Sociologia, relacionando-a à carga horária do eixo técnico de formação, parte específica do curso.

De acordo com o PPC analisado, o currículo em questão foi construído para o desenvolvimento da EPT com o objetivo de eliminar a divisão entre Educação Básica e formação profissional técnica, empregando uma formação humana integral, rompendo com a dual separação entre pensar e agir por meio do princípio da politecnia e pela articulação ciência, trabalho, tecnologia e cultura (IFPR, 2015). Contraditoriamente, o mesmo documento coloca o empreendedorismo inovador no mesmo nível de relevância da tríade ensino-pesquisa-extensão, que é o cerne da educação profissional ofertada pela rede pública, seja no Ensino Médio, Superior ou na Pós-Graduação.

No Quadro 1, em que apresentamos os objetivos do curso Técnico em Automação, vê-se essa mesma referência de promover a relação dialógica entre ensino, pesquisa, extensão e o empreendedorismo inovador para formar profissionais que contribuam para o desenvolvimento do mercado de trabalho. Essa forma de incentivo ao espírito empreendedor do estudante da EPT é criticada por Moura (2013, p. 178), pois o autor considera essa medida uma forma de validar organicamente o fato de que "[...] não há espaço para todos no mercado de trabalho e que, dessa forma, é necessário que cada indivíduo seja o mais competitivo possível".

Quanto à carga horária dedicada à formação humana e à formação técnica e profissional, verificamos que, nas disciplinas do eixo de Ciências Humanas e suas Tecnologias, há uma carga horária superior à do eixo técnico apenas no 10 ano do curso: 320 horas e $\mathbf{2 8 0}$ horas, respectivamente. No 2ㅇano a carga horária em ambos os eixos é equivalente, enquanto nas duas séries subsequentes a diferença entre elas é considerável: 320 horas de formação humana para 480 horas de formação técnica no 3o ano. No 4ำ ano são 160 horas de formação humana para 640 horas de formação técnica. Essa discrepância contradiz o que prevê o PPC do curso quanto à "[...] formação integral para uma participação crítica e ativa no mundo trabalho" (IFPR, 2015, p. 21, grifo nosso).

O quadro docente do IFPR Campus Campo Largo conta com 53 docentes das áreas da BNCC e dos eixos técnicos; são, portanto, professores licenciados e bacharéis em diversas áreas. Esses professores atuam em dois cursos de Ensino Médio Integrado (Automação e Eletromecânica), um curso Técnico em Administração na modalidade Proeja, 
cinco cursos Técnicos Subsequentes (Administração, Agroecologia, Cerâmica, Eletrotécnica, Mecânica), um curso Superior de Tecnologia em Agroecologia e um curso de Pós-Graduação em Gestão Empresarial.

No que concerne às especificidades da formação dos docentes, verificamos, por meio do website do campus, a lista de servidores e consultamos as respectivas formações no Currículo Lattes cadastrado na plataforma do Conselho Nacional de Desenvolvimento Científico e Tecnológico (CNPq). Desse modo, chegamos à informação de que 30 docentes possuem formação inicial em bacharelado nas áreas de Administração, Agroecologia, Cerâmica, Direito, Eletrotécnica e Mecânica, sendo os responsáveis pelo eixo de Formação Técnica e Profissional de todos os cursos ofertados no IFPR Campus Campo Largo, que contava com 880 alunos presenciais matriculados segundo dados do Sistema Nacional de Informações da Educação Profissional e Tecnológica (Sistec) em 3 de maio de 2019.

O quantitativo de docentes bacharéis, em sua maioria engenheiros, é condizente com a matriz curricular analisada e seu caráter tecnicista no que se refere ao tempo disponibilizado para formação técnico-profissional em detrimento da formação humana, posto que não identificamos nenhuma referência à interdisciplinaridade ou mesmo de integração com as áreas da BNCC nas ementas das disciplinas do curso.

Precisamos refletir, contudo, sobre a condição do docente que foi contratado a partir de sua formação técnica para garantir a formação específica dos cursos. Desse modo, corroboramos o que afirma Machado (2011), quando esclarece que a trajetória profissional do docente da EPT é marcada pela heterogeneidade do quadro de professores, o que exige o estabelecimento de práticas pedagógicas mais coerentes, consistentes por meio de diálogo e de efetiva participação dos docentes em programas de formação continuada.

\section{Técnico em Contabilidade - Campus Curitiba}

No campus Curitiba a oferta do curso Técnico em Contabilidade Integrado ao Ensino Médio, diferentemente dos demais cursos e campi analisados, possui três anos de duração. O Quadro 2, a seguir, apresenta as características do curso em Contabilidade Integrado ao Ensino Médio do IFPR - Campus Curitiba.

Quadro 2 - Curso Técnico em Contabilidade Integrado - Campus Curitiba

\begin{tabular}{|c|l|}
\hline Nome do curso & Técnico em Contabilidade \\
\hline Eixo tecnológico & Gestão e negócios \\
\hline Duração & 3 anos \\
\hline Carga horária & 3.880 horas \\
\hline Objetivo & $\begin{array}{l}\text { Formar profissionais Técnicos em Contabilidade que possam: [...] Exercer } \\
\text { liderança, sabendo trabalhar e coordenar equipes de trabalho [...]; Ler, } \\
\text { articular e interpretar símbolos e códigos em diferentes linguagens e } \\
\text { representações [...] Contribuir para a formação de um profissional com } \\
\text { o perfil empreendedor, capaz de fornecer informações essenciais para } \\
\text { planejar, executar, controlar e avaliar o processo produtivo. Habilitar o } \\
\text { profissional para atender às necessidades contábeis em níveis fiscais e } \\
\text { gerenciais das empresas; [...]. }\end{array}$ \\
\hline
\end{tabular}




\begin{tabular}{|c|l|}
\hline Perfil do egresso & $\begin{array}{l}\text { Executar o registro dos fatos administrativos ocorridos nas empresas } \\
\text { sob sua responsabilidade, a fim de elaborar as demonstrações } \\
\text { contábeis exigidas pela legislação. [...]. Elaborar o planejamento } \\
\text { tributário no momento da abertura da empresa ou no decorrer de } \\
\text { seu desenvolvimento; Apresentar bom relacionamento, senso crítico- } \\
\text { reflexivo, iniciativa, flexibilidade, senso de observação, auto-gestão, } \\
\text { abstração e raciocínio lógico; [...]; Possuir conhecimentos básicos nas } \\
\text { áreas específicas de direito, estatística, administração geral, área } \\
\text { financeira, informática, recursos humanos; [...] Apresentar perfil de } \\
\text { liderança, buscando o aprimoramento de características que propiciam } \\
\text { a atividade de liderança [...]. }\end{array}$ \\
\hline
\end{tabular}

Fonte: Adaptado pelos autores a partir do Projeto Político do curso Técnico em Contabilidade (IFPR, 2011c, grifos nossos).

Um dos objetivos apresentados no Quadro 2 visa a formar profissionais com perfil empreendedor, capazes de exercer liderança e utilizar adequadamente a linguagem oral e escrita como instrumento de comunicação e interação social necessária ao desempenho profissional. Nesse caso, "[...] o empreendedorismo passa a ser apresentado como sinônimo de 'autonomia' resultado de muito esforço e competência" (IWASSE, 2018, p. 112).

Objetiva-se, ainda, formar técnicos em contabilidade capazes de fornecer informações essenciais para planejar, executar, controlar e avaliar o processo produtivo e, também, compreender o meio político, social e econômico em que está inserido. Formar, então, profissionais nas especificidades do eixo técnico para que possam ser submetidos às "[...] transformações e a intensificação das condições de exploração da força de trabalho" (IWASSE, 2018, p. 112), com a flexibilidade necessária à adaptação aos moldes que lhe impuser o mercado de emprego.

No que se refere ao perfil do egresso desse curso, antes de elencar as características do profissional que se pretende formar o PPC analisado afirma que em um "[...] mundo global que exige formação geral e não específica, o currículo deverá formar profissionais de contabilidade, da Área de Gestão, em nível Técnico com competência para [...]" (IFPR, 2011c, p. 4), demonstrando uma visão reducionista da formação à instrumentação técnica para o cumprimento de determinadas funções sociais e do mercado de emprego. O Quadro 2 traz a matriz curricular do curso.

Ao analisarmos a proposta de matriz curricular para os três anos do curso Técnico em Contabilidade, percebemos que a formação técnica se sobrepõe à formação humana em todas as séries, sendo 400 horas anuais de aulas do eixo técnico para 240 horas de formação nas áreas de Ciências Humanas e Sociais Aplicadas no mesmo período. Essa disparidade é coerente com o perfil profissional proposto no PPC, porém não contempla os objetivos do curso, conforme já analisamos anteriormente.

Ao organizar-se dessa maneira, nota-se grave equívoco em termos de Currículo Integrado, pois a distribuição da carga horária das disciplinas, de acordo com a matriz curricular, indica a prioridade em se ofertar uma formação pragmática focada no ensino útil e instrumental. Observa-se, portanto, que a ideia de ensino integrado não caminha ao encontro de uma formação que prioriza o ensino na perspectiva omnilateral, como 
no caso anterior, em que há uma explícita dicotomia entre disciplinas do eixo técnico/ profissional e do eixo humano formador que não contribui para a formação de uma identidade profissional do estudante em formação (CAMBRAIA; PEDROSO, 2017).

Nesse sentido, Kuenzer (2017) questiona a respeito de como será possível compreender as questões específicas das áreas técnicas sem a devida formação em Ciências Humanas e Sociais. Segundo a autora, "[...] as disciplinas que podem fornecer elementos para a crítica e consequente apreensão das relações sociais concretas em seu caráter de totalidade, são relegadas a um lugar secundário na parte comum do currículo [...]" (KUENZER, 2017, p. 347).

A lista de docentes disponível no website do Campus Curitiba, cujas informações foram atualizadas em janeiro de 2019, elenca um total de 210 professores. Após nossa análise da lista pública de professores quanto à sua formação inicial, verificamos a existência de 141 docentes bacharéis e tecnólogos de áreas como Enfermagem, diversas Engenharias, Direito, Contabilidade, Fisioterapia, Administração, Informática, Odontologia, Arquitetura e Urbanismo, Tecnólogos em Gestão Pública, Mecânica, Design de Móveis, Construção Civil, Radiologia, Processamento de Dados, Informática e Telecomunicações.

Nesse contexto, mesmo diante de uma tentativa de introdução de um currículo integrado, a maior probabilidade é que não ocorra uma formação integral do estudante, levando em conta

a) fragmentação dos conhecimentos - em que cada disciplina desenvolve seu plano de ensino e, na maioria dos casos, pouco se diferencia de um curso de Bacharelado. Isso ocorre, principalmente, devido à dificuldade de interação entre os professores/formadores dos diferentes núcleos; b) os descompassos entre teoria e prática (CAMBRAIA; PEDROSO, 2017, p. 7).

Diante da diversidade de formações em áreas técnicas distintas, ressaltamos que, considerando a complexidade da formação docente, julgamos pertinente refletirmos sobre os aspectos sociais e econômicos da educação e, principalmente, da EPT. A esse respeito, Araújo e Oliveira (2017) discorrem que

[...] a educação escolar situada na dimensão da superestrutura (ideológica e política) tem o papel de formar os trabalhadores ou os futuros trabalhadores e segue, para tanto, as necessidades impostas pela infraestrutura (base produtiva - econômica) o que implica, por sua vez, na existência de professores cuja "formação" seja condizente para o exercício adequado de determinadas práticas de ensino, considerando os imperativos contemporâneos para a formação e reprodução social da força de trabalho (p. 90).

Com base nessa passagem, ganham relevo as propostas para que a formação continuada para docentes seja construída coletivamente do processo que emana da discussão entre equipe gestora e pedagógica, com vistas ao exercício de uma educação crítica não restrita aos limites estruturais do Ensino Instrumental hegemônico. As análises desenvolvidas por Cambraia e Pedroso (2017) indicam movimentos que visam a desenvolver ações cuja experiência adquirida suplante a propositura de formação continuada não restrita aos limites do ensino instrumental. Trata-se de um esforço para proporcionar a formação de um profissional reflexivo. 
Busca-se essa formação por meio do Programa Desenvolvimento Profissional Docente na Licenciatura em Computação - DPDLiC. Com a premissa de provocar rupturas com essas dificuldades apresentadas anteriormente, o DPDLiC "é um protótipo de formação continuada presencial e on-line" (CAMBRAIA; PEDROSO, 2017, p. 8).

De forma mais detida, essas ações, que visam a proporcionar uma formação dos professores bacharéis por meio do DPDLiC, representam

[...] uma tentativa intencional de organizar um processo coletivo de estudo, planejamento e ação entre professores pesquisadores na perspectiva de avançar na direção de romper com a racionalidade técnica, que cria automatismos e fragmentação da formação docente (CAMBRAIA; ZANON, 2018, p. 20).

Os resultados dessa formação continuada apresentam relativos êxitos no sentido de promover rupturas com a formação tecnicista no Iffar. Por meio do DPDLiC, segundo Cambraia e Zanon (2018), impulsionou-se o desenvolvimento da pesquisa sobre a prática profissional docente. Deste modo, em contraposição ao tecnicismo, a formação continuada visa à "formação docente de forma complexa e dialética, realizada na interlocução entre sujeitos com formação e prática diferenciada, que participam e se envolvem ativamente no processo de reconstrução do ensino e da aprendizagem" (CAMBRAIA; ZANON, 2018, p. 21).

Destacamos, ainda, a verticalização do ensino que, no caso do campus em tela, perpassa do Ensino Médio à Pós-Graduação stricto senso em nível de Mestrado. Essa prerrogativa faz parte das finalidades e das características dos Institutos Federais regulamentadas pela Lei № 11.892/2008, em sua Seção II, artigo 60, inciso III, determinando a obrigatoriedade dos IFs em "[...] promover a integração e a verticalização da educação básica à educação profissional e educação superior, otimizando a infraestrutura física, os quadros de pessoal e os recursos de gestão" (BRASIL, 2008b, p. 1).

Desse modo, a atuação profissional docente passa por um inevitável processo de precarização, pois, uma vez que são acrescidos outros níveis de ensino, a condição de trabalho é degradada tanto pela transição em diversos turnos, flexibilizando sua jornada de trabalho, quanto pela multiplicidade de currículos a serem apreendidos, a participação em diversos colegiados e a consequente intensificação de suas funções. Para Araújo (2018, p. 91), a precarização consolida-se por meio de processos complexos e dinâmicos que "[...] geram sofrimento psíquico provocado pelas cobranças e imposições dos sistemas de ensino, das avaliações de larga escala e, por fim, pelo alargamento das competências que são exigidas do professor para executar o seu trabalho".

\section{Curso Técnico em Administração - Campus de Pinhais}

O Curso Técnico em Administração Integrado ao Ensino Médio do IFPR - Campus Pinhais -, foi criado em 2014 e teve sua primeira turma no ano de 2015. Seu PPC foi elaborado com base em uma ampla pesquisa a respeito dos aspectos econômicos, sociais e políticos do município, desenvolvida junto aos representantes da indústria, do comércio e dos serviços, pela Prefeitura de Pinhais em parceria com a Paraná Pesquisas. Os estudos demonstraram que Pinhais seria uma cidade promissora para a formação de 
trabalhadores no eixo tecnológico de Gestão de Negócios. A seguir, por meio do Quadro 3, é possível verificar as características do curso Técnico em Administração Integrado ao Ensino Médio oferecido pelo IFPR - Campus Pinhais.

Quadro 3 - Curso Técnico em Administração Integrado - Campus Pinhais

\begin{tabular}{|c|c|}
\hline Nome do curso & Curso Técnico em Administração \\
\hline Eixo tecnológico & Gestão e Negócios \\
\hline Duração & 4 anos \\
\hline Carga horária & 3.173 horas-relógio \\
\hline Objetivo & $\begin{array}{l}\text { Formar integralmente profissionais aptos a exercerem plenamente sua } \\
\text { autonomia de conhecimentos da área de Administração e da educação } \\
\text { básica [...]; Formar um profissional de nível técnico com capacidade de } \\
\text { atuar nas atividades administrativas, dando a ele conhecimentos teórico- } \\
\text { práticos que o capacitem a executar, pensar, planejar, dirigir, supervisionar } \\
\text { e controlar a qualidade dos produtos ou serviços relativos à Administração; } \\
\text { Promover a articulação do quadripé ensino, pesquisa, extensão e inovação, } \\
\text { por intermédio do exercício da pesquisa como princípio pedagógico [...] }\end{array}$ \\
\hline Perfil do egresso & $\begin{array}{l}\text { O técnico em Administração será um profissional capaz de articular } \\
\text { conhecimentos e práticas da gestão de finanças, de processos produtivos, } \\
\text { de recursos humanos, de marketing e do planejamento, habilidades que } \\
\text { se somam a um perfil empreendedor, crítico, ético e comprometido com a } \\
\text { responsabilidade social e ambiental. [...]. }\end{array}$ \\
\hline
\end{tabular}

Fonte: Adaptado pelos autores a partir do Projeto Político do curso Técnico em Administração (IFPR, 2018).

O curso Técnico em Administração Integrado, apresentado no Quadro 3, demonstra que este foi criado sob a égide da inserção de seus formandos no mercado de trabalho, seja pelo aproveitamento desses profissionais nas empresas regionais, seja pelo desenvolvimento individual pelo empreendedorismo proposto no curso. A partir dessa constatação, evidenciamos que os objetivos do curso indicam que essa proposta buscou apresentar meios para o desenvolvimento integral do estudante para torná-lo um trabalhador emancipado, preparado para atuar na sociedade e exercer sua profissão de forma ética e responsável, exercendo sua "[...] autonomia de conhecimentos da área de Administração e da educação básica", ancorados em elementos que visam a propiciar ao estudante conhecimentos teórico-práticos "[...] que o capacitem a executar, pensar, planejar, dirigir, supervisionar e controlar", promovendo a "[...] articulação do quadripé ensino, pesquisa, extensão e inovação", de modo a possibilitar a "verticalização dos estudos" (IFPR, 2018, p. 15).

Com base na análise documental, encontramos, no texto do PPC, elementos que nos remetem a uma tentativa de ofertar a Educação Básica integrada à formação profissional que busca superar a "[...] dualidade entre cultura geral e cultura técnica, assumindo o conceito de politecnia" (CIAVATTA, 2008, p. 4). Embora o perfil do egresso apresente mais aspectos técnicos, nele também encontramos a premissa de que seu formando possa compreender e atuar na sociedade moderna com capacidade humanística relacionada às áreas básicas do Ensino Médio e que deva ser profissional com "[...] perfil empreendedor, crítico, ético e comprometido com a responsabilidade social e ambiental" (IFPR, 2018, p. 15). 
Para alcançar os objetivos propostos e formar Técnicos em Administração com o perfil profissional descrito, o PPC indica a elaboração de um currículo pensado para concretizar a indissociabilidade entre Ensino, Pesquisa, Extensão e Inovação, articulando saberes do Ensino Médio, etapa final da Educação Básica e da EPT. Desse modo, a matriz curricular descrita no Quadro 3, foi construída com base em pressupostos pedagógicos norteados pela "[...] concepção integral de ser humano que, no mundo do trabalho, aprende, socializa-se, exerce sua cidadania e, portanto, forma-se" (IFPR, 2018, p. 16).

Ao nos debruçarmos no projeto do curso, o primeiro aspecto que nos chamou atenção foi a carga horária dedicada à formação em Língua Estrangeira (Inglês e Espanhol). Nos três primeiros anos do curso são ofertadas 120 horas anuais para cada uma dessas disciplinas, e no 4ำ ano são oportunizadas mais 80 horas para cada componente, totalizando 880 horas ao final do curso. Enfatizamos que, das disciplinas da BNCC, apenas Língua Portuguesa, Língua Inglesa e Língua Espanhola são ofertadas em todas as séries nesse curso.

Ao fazermos uma comparação da carga horária dedicada às disciplinas do eixo de Ciências Humanas e Sociais Aplicadas, assim como aos demais cursos analisados, podemos observar que estas são inferiores à carga horária da Formação Técnica e Profissional. Ao analisarmos, no PPC, entretanto, a fundamentação teórica informada para a concepção do currículo do curso, constatamos que este foi organizado com base nas Diretrizes Curriculares Nacionais para a Educação Profissional Técnica de Nível Médio, o que indica a utilização da interdisciplinaridade, o reconhecimento das diversidades e a indissociabilidade entre teoria e prática como recursos metodológicos.

É preciso, no entanto, haver integração de conhecimentos científicos teóricos e práticos do Ensino Médio com temáticas do eixo técnico profissional sob o exercício da interdisciplinaridade, empregando uma formação omnilateral. Sobre essa perspectiva, Saviani (2003) esclarece que

[...] torna-se possível formar profissionais não apenas teórica, mas também praticamente num processo em que se aprende praticando, mas, ao praticar, se compreendem, de forma cada vez mais aprofundada, os princípios científicos que estão direta e indiretamente na base desta forma de se organizar o trabalho na sociedade (p. 142).

Notamos que no PPC do curso consta que as atividades de pesquisa, extensão e inovação realizam-se de forma interdisciplinar por meio de "[...] projetos, eventos (científicos, culturais e esportivos), visitas técnicas, aulas práticas, estudos de caso e cursos (presenciais e a distância)" (IFPR, 2018, p. 29). Outra proposta de integração adotada como estratégia metodológica são as simulações, as práticas laboratoriais e a elaboração de produtos que estão presentes nas ementas das disciplinas anexas ao PPC.

No website $^{6}$ do campus localizamos uma lista com 28 docentes pertencentes ao quadro de servidores dessa unidade. Destes, 13 professores possuem formação inicial em bacharelado. Machado (2011) afirma que a execução de currículo integrado demanda formação docente continuada que possa garantir o

Disponível em: http://pinhais.ifpr.edu.br/. Acesso em: 10 abr. 2019. 
[...] necessário trabalho coletivo e colaborativo dos professores de conteúdos da educação geral e profissional; a compreensão de como desenvolver os princípios educativos do trabalho, da ciência, da tecnologia e da cultura; o diálogo entre teoria e prática; o pensar e o agir na lógica da interdisciplinaridade; a sintonia com o desenvolvimento tecnológico e o contexto socioeconômico e ambiental (p. 694).

Conforme analisamos, a proposta desse curso foi a que mais se aproximou dos aspectos teóricos e normativos da educação profissional com vistas à formação integral do homem. A formação docente, neste caso, remete-nos ao fato de que, embora com uma proposta curricular coerente aos elementos pedagógicos fundamentais para a oferta de um curso em que, de fato, haja integração e interdisciplinaridade, sua ênfase atende mais à regulação do mercado, como um serviço, do que prioriza a educação como direito social.

Nossa intenção não é tecermos julgamento à instituição, tampouco ao docente, mas alertarmos para o movimento ideológico do capital de fazer-se presente na definição das políticas de educação, principalmente na Educação Profissional. A esse respeito, Frigotto (2006, p. 46) afirma que "[...] não é inocente o ideário pedagógico dos parâmetros e diretrizes curriculares e dos processos de avaliação centrados na concepção produtivista e empresarial das competências, da competitividade e da empregabilidade".

Pelo exposto, consideramos que a atuação do professor bacharel na modalidade de curso Técnico Integrado ao Ensino Médio ofertado no IFPR, torna premente a realização de discussões sobre políticas de formação pedagógicas para esses profissionais, pois o trabalho docente, em qualquer nível, exige formação específica e, na educação profissional e tecnológica, não é diferente. Assim, ao correlacionarmos as informações do resumo nos quadros quanto aos objetivos, ao perfil profissional de conclusão, à carga horária do curso e à formação dos docentes, observamos que há uma mescla dos princípios da gestão e da organização do trabalho dos modelos de produção taylorista-fordista e toyotista, com vistas à melhoria do processo de acumulação do capital por meio da combinação de trabalho precário e trabalho qualificado. A concepção do que significa competência fora alterada pela necessidade de conhecimento teórico, que passou a fazer parte da formação do trabalhador (KUENZER, 2008).

De acordo com Kuenzer (2008, p. 27), essa nova compreensão de competência “[...] não atende necessariamente apenas ao capital, uma vez que impacta positivamente a formação dos trabalhadores, em razão do que são geradas novas necessidades relativas à formação dos professores de educação profissional" para agregar à formação do trabalhador uma gama maior de conhecimentos teóricos que os prepare para lidar com problemas não somente da prática laboral, mas também social e, ainda, compreender o trabalho intelectual trazido pelo uso das novas tecnologias (KUENZER, 2008).

Ao considerarmos as ponderações realizadas por (KUENZER, 2008), contudo, percebemos que o avanço tecnológico gera novas especificidades profissionais, o que exige uma formação adequada às necessidades e às características do mercado de emprego. Nesse caso, a formação pedagógica do docente não recebe a devida atenção pelas ins- 
tituições de ensino, prevalecendo a formação científico-tecnológica obtida pelo professor quando da sua formação inicial. No caso específico dos campi do IFPR analisados, a prevalência de professores bacharéis nos cursos de nível médio integrado gera contradições que, a rigor, tendem a negar a formação adequada preconizada para a Educação Básica da qual o Ensino Médio é parte constitutiva.

\section{CONSIDERAÇÕES FINAIS}

Historicamente, o Brasil é negligente no que se refere às políticas de formação docente, especialmente para os professores que atuam na EPT, pois parte-se da premissa de que o conhecimento técnico específico da área de formação é suficiente para o ensino em sala de aula, negando ao docente a construção de uma carreira profissional e suas especificidades. Machado (2011, p. 703) assevera que é preciso “[...] desenvolver formação inicial e continuada que contribua para dar o sentido de pertencimento ao grupo social dos professores da EPT e que dialogue com as expectativas, realidades e desafios do trabalho da docência neste campo educacional".

Nessa perspectiva, Machado (2011, p. 690) esclarece, ainda, que a formação de profissionais docentes para atuação da EPT “[...] é decisiva para que a atual política de expansão, interiorização e democratização dessa modalidade educacional se efetive com qualidade social, produção de conhecimentos, valorização docente e desenvolvimento local, integrado e sustentável". É, desse modo, um meio para a efetivação de um Ensino Médio Técnico Integrado como cerne de uma educação profissional com vistas à emancipação humana.

Por meio deste artigo evidenciamos que o objetivo do IFPR é atender às necessidades de formação profissional para o mercado de emprego, com oportunidades de qualificação para jovens concluintes do Ensino Fundamental, destinando um percentual maior de oferta de vagas para a modalidade de ensino analisada. Demonstramos que a maior parte das vagas ocupadas pelos alunos ingressos dá-se pela via do sistema de cotas de inclusão social e racial. Por isso, consideramos fundamental a adoção de medidas que possibilitem a articulação ciência, trabalho e cultura que conduzam à superação da dualidade verificada entre a Educação Básica e a Educação Profissional.

Dos três cursos de Ensino Médio Técnico Integrado à Educação Profissional, após análise da quantidade de horas-aula destinada à formação profissional, observamos que a carga horária das disciplinas "técnicas" é superior à ofertada nas disciplinas no eixo Ciências Humanas e Sociais Aplicadas (História, Geografia, Sociologia e Filosofia). No Campus Pinhais o curso investigado apresenta uma boa fundamentação teórica em seu PPC. A oferta das disciplinas de formação ocorre somente até o 30 ano, o que representa uma contradição quanto aos objetivos e ao perfil profissional pretendido no que diz respeito aos aspectos da formação integral para "[...] compreender e atuar na sociedade moderna com capacidade humanística relacionada as áreas básicas do ensino médio" (IFPR, 2018, p. 15), enquanto no Campus Campo Largo, as disciplinas de História e Geografia não são disponibilizadas no 4음 ano do curso.

No que se refere à formação inicial dos docentes do IFPR, verificamos que muitos possuem Graduação em bacharelado, predominantemente em engenharias de diversas áreas, ou docentes oriundos de cursos tecnólogos. Temos, na Educação Básica, a atua- 
ção de professores cuja formação de origem não prepara para o exercício da docência, mas, uma vez contratados, necessitam constituir sua identidade profissional, pertencer a uma classe de trabalhadores e fazer parte do grupo no qual atuam, assim como os professores licenciados.

Essas questões são pertinentes na medida em que a profissão docente, como qualquer outra, está inserida no contexto das contradições do modo de acumulação flexível do sistema capitalista contemporâneo. Dessa forma, analisar uma política pública relevante por meio da criação dos Institutos Federais e, consequentemente, do IFPR, significa apreender que ações que visam a atender à lógica do capital não podem, na mesma proporção, contemplar a necessidade de uma formação politécnica na perspectiva omnilateral.

Por fim, tanto os elementos destacados na análise dos Projetos Pedagógicos de Cursos quanto os aspectos relativos à formação docente, demonstram a vulnerabilidade da educação profissional brasileira. As permanentes reformas ao longo das décadas, impulsionadas pela modernização da sociedade em geral e, especialmente, pela reestruturação do modo de produção, levaram a educação à condição de que cada vez mais "[...] na formulação teórica e nas políticas concretas, instaura-se uma profunda regressão ao produtivismo, fragmentação e economicismo" (FRIGOTTO, 2006, p. 49).

\section{REFERÊNCIAS}

ARAÚJO, J. J. C. do N. A precarização da formação de professores para a Educação Básica no Instituto Federal de Ciência, Educação e Tecnologia do Acre - Campus Cruzeiro do Sul. 2018. 261 f. Tese (Doutorado em Educação) - Universidade Federal do Amazonas, Manaus, 2018.

ARAÚJO, R. B.; OLIVEIRA, H. C. de. Implicações da lógica da teoria do capital humano sobre o trabalho educativo: um olhar histórico. In: Pedagogia em Foco, Iturama, v. 12, n. 7, p. 88-101, jan./jun. 2017.

BRASIL. Lei № 11.741, de 16 de julho de 2008. Altera dispositivos da Lei no 9.394, de 20 de dezembro de 1996, que estabelece as diretrizes e bases da educação nacional, para redimensionar, institucionalizar e integrar as ações da educação profissional técnica de nível médio, da educação de jovens e adultos e da educação profissional e tecnológica. Diário Oficial da União: seção 1, Brasília, DF, n. 136, p. 5-6, 17 jul. 2008a.

BRASIL. Lei № 11.892, de 29 de dezembro de 2008. Institui a Rede Federal de Educação Profissional, Científica e Tecnológica, cria os Institutos Federais de Educação, Ciência e Tecnologia, e dá outras providências. Diário Oficial da União: seção 1, Brasília, DF, n. 253, p. 1, 30 dez. 2008b.

CAMBRAIA, A. C.; PEDROSO, E. Construção identitária do professor de computação: integração curricular dos documentos a ação. In: Revista Contexto \& Educação, v. 32, n. 103, p. 5-28, 1 dez. 2017.

CAMBRAIA, A. C.; ZANON, L. B. Desenvolvimento profissional docente numa Licenciatura: interlocuções sobre o projeto integrador. Rev. Bras. Educ., Rio de Janeiro, v. 23, e230043, 2018. Disponível em: http:// www.scielo.br/scielo.php?script=sci_arttext\&pid=S1413-24782018000100235\&lng=en\&nrm=iso. Acesso em: 2 jul. 2020.

CIAVATTA, M. A formação integrada: a escola e o trabalho como lugares de memória e de identidade. In: Trabalho Necessário, Niterói, ano 3, n. 3, p. 1-20, 2005.

CIAVATTA, M. Implicações curriculares frente ao contexto político e legal do ensino médio: questões atuais. Texto preparado para o Seminário "O currículo de educação básica em questão". Curitiba: SEE-PR, 10 out. 2008. (Mimeo).

CIAVATTA, M. Caminhos da educação socialista. Trabalho Necessário, Niterói, a. 16, n. 29, p. 28-53, 2018. DOI: https://doi.org/10.22409/tn.16i29.p4553. 
DAMASCENA, E. A.; NASCIMENTO, A. C. V. do; MOURA, D. H. Formação de professores para a educação profissional: o que apontam os dispositivos legais mais recentes (2015-2017). In: COLÓQUIO NACIONAL, 4., COLÓQUIO INTERNACIONAL, A PRODUÇÃO DO CONHECIMENTO EM EDUCAÇÃO PROFISSIONAL, 1., 2017, Natal. Anais eletrônicos [...]. Natal: IFRN, 2017. Disponível em: https://ead.ifrn.edu.br/coloquio/ anais/2017/trabalhos/eixo1/E1A33.pdf. Acesso em: 20 maio 2019.

DELLA FONTE, Sandra Soares. A formação humana em debate. Educ. Soc. Campinas, v. 35, n. 127, p. 379-395, jun. 2014. Disponível em: http://www.scielo.br/scielo.php?script=sci_arttext\&pid=S0101-73302014000200003\&lng=en\&nrm=iso. Acesso em: 2 jul. 2020.

FERRETTI, C. J. A implementação dos cursos técnicos integrados no Instituto Federal de Educação, Ciência e Tecnologia do Paraná. In: Educere et Educare, Cascavel, v. 11, n. 23, p. 1-18, jul./dez. 2016.

FRIGOTTO, G. Anos 1980 e 1990: a relação entre o estrutural e o conjuntural e as políticas de educação tecnológica e profissional. In: FRIGOTTO, G.; CIAVATTA, M. (org.). A formação do cidadão produtivo: a cultura de mercado no ensino médio técnico. Brasília: Instituto Nacional de Estudos e Pesquisas Educacionais Anísio Teixeira, 2006. p. 25-53.

FRIGOTTO, G. A relação da educação profissional e tecnológica com a universalização da educação básica. In: Educação \& Sociedade, Campinas, v. 28, n. 100, Especial, p. 1.129-1.152, out. 2007.

GIL, Antonio Carlos. Como elaborar projeto de pesquisa. 4. ed. São Paulo: Atlas, 2002.

IFPR. Instituto Federal do Paraná. Resolução № 13/2011. Aprova a mudança e consolida o Estatuto do IFPR. Curitiba, 2011a. Disponível em: http://reitoria.ifpr.edu.br/wp-content/uploads/2012/07/estatuto. pdf. Acesso em: 24 jan. 2019.

IFPR. Instituto Federal do Paraná. Resolução № 54, de 21 de dezembro de 2011. Dispõe sobre a Organização Didático-Pedagógica da Educação Profissional Técnica de Nível Médio e Formação Inicial e Continuada de Trabalhadores no âmbito do Instituto Federal do Paraná - IFPR. 2011b. Disponível em: http://campolargo.ifpr.edu.br/wp-content/uploads/2014/04/ODP-Resolu\%C3\%A7\%C3\%A3o-n\%C2\%BA-54.11-COM-ATUALIZA\%C3\%87AO-2017.pdf. Acesso em: 24 jan. 2019.

IFPR. Instituto Federal do Paraná. Curso Técnico em Contabilidade Integrado ao Ensino Médio do IFPR Campus Curitiba. 2011c. Disponível em: http://curitiba.ifpr.edu.br/wp-content/uploads/2010/12/Plano-de-Curso-Contabilidade.pdf. Acesso em: 24 jan. 2019.

IFPR. Instituto Federal do Paraná. Projeto Pedagógico do curso técnico em automação industrial. Campo Largo, 2015. Disponível em: https://drive.google.com/file/d/1tbu_TzzMt1iljJYZGDr7NC1wLQqr-Q_k/view. Acesso em: 24 jan. 2019.

IFPR. Instituto Federal do Paraná. Projeto Político Pedagógico 2017. Campus Curitiba. 2017. Disponível em: http://curitiba.ifpr.edu.br/wp-content/uploads/2018/02/PPP-vers\%C3\%A3o-fevereiro-de-2017.pdf. Acesso em: 24 jan. 2019.

IFPR. Instituto Federal do Paraná. Projeto Pedagógico do Curso Técnico em administração forma de oferta: articulada integrada. Pinhais, 2018. Disponível em: https://drive.google.com/file/d/1ZTy50Cg5laADGWgUCC0xqg19kZ1hOOFV/view. Acesso em: 24 jan. 2019.

IWASSE, L. F. A. Educação e trabalho: políticas públicas de ensino e formação de professores no Brasil. 2018. 148 f. Dissertação (Mestrado em Ensino) - Universidade Estadual do Paraná, Paranavaí, 2018.

KUENZER, A. Z. Formação de professores para a educação profissional e tecnológica: perspectivas históricas e desafios contemporâneos. In: INEP. Formação de professores para educação profissional e tecnológica. Brasília: Instituto Nacional de Estudos e Pesquisas Educacionais Anísio Teixeira, 2008. p. 19-40. V. 8. KUENZER, A. Z. A formação dos trabalhadores no espaço de trabalho. In: Trabalho Necessário, Niterói, ano 14, n. 25, p. 37-52, 2016.

KUENZER, A. Z. Trabalho e escola: a flexibilização do ensino médio no contexto do regime de acumulação flexível. In: Educação \& Sociedade, Campinas, v. 38, n. 139, p. 331-354, abr./jun. 2017.

MACHADO, L. R. de S. O desafio da formação dos professores para EPT e Proeja. In: Educação \& Sociedade, Campinas, v. 32, n. 116, p. 689-704, jul./set. 2011.

MANACORDA, M. A. Marx e a pedagogia moderna. Campinas: Alínea, 2007.

MARX, K. O capital: crítica da economia política. Livro I. V. I: o processo de produção capitalista. São Paulo: Nova Cultural, 1996.

MARX, K. Manuscritos econômico-filosóficos. Trad. Jesus Ranieri. 1. ed. 4. reimpr. São Paulo: Boitempo, 2004.

MOURA, D. H. Ensino médio integrado: subsunção aos interesses do capital ou travessia para a formação humana integral? In: Educação e Pesquisa, São Paulo, v. 39, n. 3, p.705-720, 2013. 


\section{\& Contexto}

NETTO, J. P. Relendo a teoria marxista da história. In: SAVIANI, D.; LOMBARDI, J. C.; SANFELICE, J. L. (org.). História e história da educação: o debate teórico-metodológico atual. Campinas: Autores Associados; HISTEDBR, 1998. p. 74-84.

RAMOS, M. N. A educação de trabalhadores no Brasil contemporâneo: um direito que não se completa. In: Germinal: Marxismo e Educação em Debate, Salvador, v. 6, n. 2, p. 65-76, dez. 2014.

SAVIANI, D. Sobre a concepção de politecnia. Rio de Janeiro: Fundação Oswaldo Cruz, 1989.

SAVIANI, D. O choque teórico da politecnia. In: Trabalho, Educação e Saúde, Rio de Janeiro, v. 1, n. 1, p. 131-152, mar. 2003.

SAVIANI, D. História das ideias pedagógicas no Brasil. 4. ed. Campinas: Autores Associados, 2013.

SCHLESENER, A. H. Revolução e cultura em Gramsci. Curitiba: UFPR, 2002. 